\title{
A LONG PULSE LINAC FOR THE SECOND PHASE OF DARHT*\#
}

\author{
E.L. Burgess, J.D. Comins, W.M. Fawley, D.V. Munson, M. Nyman, L.T. Jackson, C. Peters, \\ L. Reginato, H.L. Rutkowski ${ }^{+}$, M.C. Vella, W. Waldron, S.S. Yu, \\ Lawrence Berkeley National Laboratory, One Cyclotron Road, Berkeley, CA \\ Yu-Jiuan Chen, T. Houck, Lawrence Livermore National Laboratory, \\ 7000 East Ave., Livermore, CA 94550 \\ R. Briggs, Science Application International Corporation, 7041 Koll Center Pkwy, Pleasanton, CA \\ D. Birx, Science Research Laboratory, 3300 Crismore Lane, Oakley, CA
}

\begin{abstract}
We present the design for an induction linac that is fed by a long pulse injector that will generate a $20 \mathrm{MeV}, 2 \mathrm{kA}$, $2 \mu$ s electron beam pulse for the DARHT second axis at Los Alamos National Laboratory. The accelerator cells are shielded gap cavities with Mycalex insulators and Metglas cores. A large bore (14") block of eight cells follow the injector while the remaining 80 cells have a 10" bore. Blocks of eight cells are interspersed with intercells that provide pumping, diagnostics and space for cell removal. RF properties of the cells have been calculated and measured. Response to BBU modes and corkscrew have been calculated. Design details of the cells, solenoids, corrector coils, intercells and pulsers will be presented along with prototype data.
\end{abstract}

\section{INTRODUCTION}

The induction linear accelerator section of the DARHT second axis accelerator consists of 88 induction cells arranged axially into 11 cell blocks of 8 cells each. The entire accelerator inside the building is shown in fig.1.

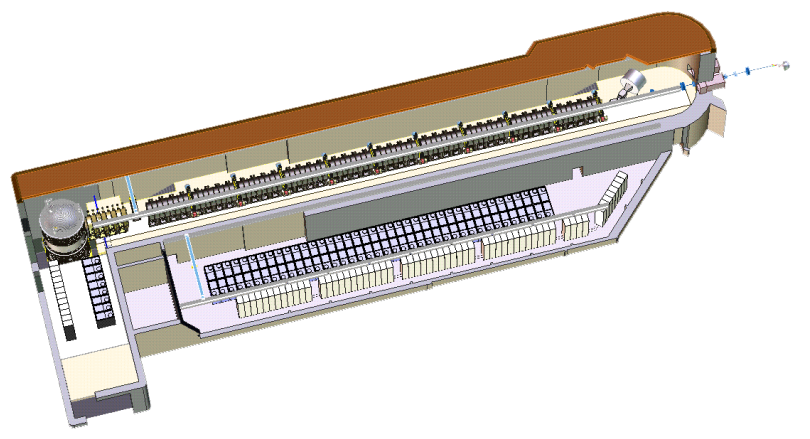

Fig. 1 DARHT Second Axis Accelerator System

*Dual Axis Hydrodynamics Test

\#This work was supported by the U.S. Department of Energy

under Contract No. DE-ACO3-76F00098.

+Email: $\underline{\text { HLRutkowski@lbl.gov }}$
The injector is at the left. It is a $3.2 \mathrm{MV}$ diode which provides the induction linac with a $2 \mathrm{kA}$ electron beam. The subject of this paper is the induction linac itself which adds $16.8 \mathrm{MeV}$ to the beam energy. An intercell is placed between each pair of cell blocks to provide vacuum pumping and a removable section to allow removal of cells for repair. As can be seen from fig.1, a large gap exists between the first and second cell block. This is to provide space for a beam-pulse-head-dump which will be designed and built by Los Alamos National Laboratory. The purpose of this dump is to lose the risetime portion of the beam pulse (approx. 400ns) in a non destructive way. The flat portion of the beam pulse is just longer than $2 \mu \mathrm{s}$. Fig.1 shows the pulsers and the electrical racks for the linac cells at a level below the accelerator. The pulsers and racks for the first eight cells are shown above the injector Marx generator tank. Downstream of the accelerator is a beam chopper system being developed by Lawrence Livermore National Laboratory to chop four short pulses out of the $2 \mu$ s macropulse and to dump the rest of the beam. The cells and pulsers are being designed to allow an upgrade in current to $4 \mathrm{kA}$, if needed, without serious modification.

\section{PHYSICS DESIGN ISSUES}

The issues most important to the physics design of the linac are generation of ions by spilled beam, beam breakup (BBU) instability, corkscrew motion of the beam centroid, and emittance growth. Spilled beam or halo may generate ions that could disrupt the transport of the beam or backstream into the injector cathode. Ions generated by beam loss can also create breakdown in the gap-insulator zone. BBU is a result of resonant coupling between transverse beam motion and TM cavity modes in the cells. It can be reduced by increasing pipe diameter decreasing 
the accelerating gap, reducing insulator dielectric constant, or increasing the solenoid transport field. Corkscrew motion comes from a combination of solenoid field misalignment and varying beam energy. Emittance growth can come from large beam envelope oscillations, non-linear focusing fields and non-uniform radial beam density. In the sections below we discuss how the cells are designed to avoid these problems.

\section{ACCELERATOR CELLS}

\section{Injector Cells}

There are two types of induction cells in the linac. The first block of 8 are called "injector cells" while the remaining 80 are called "standard cells". The part of the linac immediately after the injector is most susceptible to ion generation from beam spill and BBU generation because the beam is large and transport field must be low. The injector cell is shown in fig. 2 a.

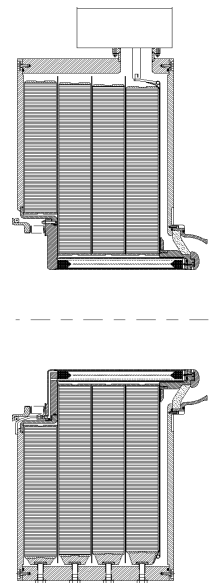

a)
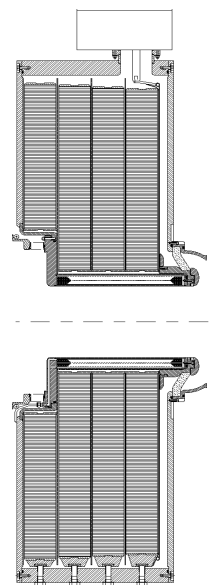

b)
Fig. 2 Injector Cell a), Standard Cell b)

The main distinctive feature of the cell is a 14 inch beam pipe diameter compared to the 10 inch pipe in the standard cell. The reasons for the larger pipe are: less generation of ions from spilled beam, smaller probability of gap breakdown from spilled beam, and reduction of transverse mode impedances that contribute to BBU. The solenoid transport field cannot be raised too rapidly at low beam energies because of possible emittance growth. The scaling of the transverse mode impedance for a pillbox cavity goes as $\mathrm{W} / \mathrm{b}^{2}$ where $\mathrm{W}$ is the accelerating gap length and $b$ is the pipe radius. AMOS calculations of the dominant mode impedances for these cells give values $180 \Omega / \mathrm{m}$. The beam pipe is stainless steel and the body of the cell is aluminium. A prototype of the cell using an insulator different from the final design geometry is being tested for beam spill effects at the THOR machine at Los Alamos. The insulator is Mycalex (a glass-mica mixture) the cross section of which is a section of a cone that has a $30^{\circ}$ angle between the electric field lines and the insulator surface to drive electrons away from the surface. The original injector cell prototype used a backward curved insulator geometry in an effort to create space for a diagnostic station in each cell and to provide some frequency shifting of the TM modes with respect to the standard cells. However, high voltage testing showed that this cell required repeated conditioning after being turned off and that voltage retreat was required after a breakdown to recondition. It was determined that diagnostics were not needed in each cell. Therefore it was abandoned.

The ferromagnetic material is Allied Signal 2605 SC Metglas. The cores are 4 inches wide and tape wound with 2.5-4 $\mu$ thick Mylar insulation. The injector cells have fewer volt-sec of core material then the standard cells and operate at $173 \mathrm{kV}$. There are four cores in each cell each of which is radially continuous and immersed in dielectric oil. Damping ferrites to reduce the Q's of TM modes are placed on the oil side of the insulator interface. There are four current feeds to the cores to prevent quadrupole moments from being induced that could perturb the beam.

The maximum enhanced electric field stress on the negative electrode is $78 \mathrm{kv} / \mathrm{cm}$ and the surface gradient on the insulator is $43 \mathrm{kv} / \mathrm{cm}$. The insulator is epoxied to the metal components to ensure that oil-vacuum leaks will not occur.

\section{Standard Cells}

Eighty of the eighty eight cells are of the design in fig. $2 b)$. There are three major differences with the other cell design. The beam pipe is 10" diameter. The Metglas cores have smaller ID but the same OD. Finally, the solenoid has twice as many layers because higher transport fields are needed at higher energies. The insulator and gap geometries are the same. The solenoids are water cooled and capable of $0.22 \mathrm{~T}$ maximum.

The design current has been reduced to $2 \mathrm{kA}$ from $4 \mathrm{kA}$ but the design has been left unchanged to allow the possibility of upgrading in the future to $4 \mathrm{kA}$. The standard cells operate at $193 \mathrm{kV}$ and the maximum enhanced field stress on the negative electrode in the gap is $85 \mathrm{kV} / \mathrm{cm}$.

\section{Intercells}

The intercells are metal boxes, that allow pumping to achieve the $10^{-7}$ Torr required beamline vacuum, and to create a section that can be removed transversely from the beamline making space to slide the interlocking induction cells out for repair. The intercell is 17 " long and contains a 6 " long, $0.25 \mathrm{~T}$ solenoid to reduce ripple in the magnetic transport line. Between the intercell and the first induction cell of the next block is a diagnostic ring containing beam position monitors and B-dot diagnostics. Current return rods are built into the intercells to allow for pumping and yet shield the beam from the cavity. 


\section{PULSERS}

Each cell is driven by a pulser that is a four stage Marx generator each stage of which is a seven capacitor pulse forming network (PFN). The pulser is capable of driving a $2.4 \mu$ s pulse into a $20 \Omega$ matched load at $200 \mathrm{kV}$ and 10 kA. The PFN impedance is tapered to handle the non linear core magnetizing current. The PFN inductance is tuned by insertion of a copper tube to maximize the voltage flatness up to $\pm 0.5 \%$ when the pulser is attached to the cell. The cell cores will be individually tested and selected so that individual tuning for each pulser/cell combination is not required. Components in the pulser are being rated conservatively to achieve long life and high reliability.

\section{MOUNTING AND ALIGNMENT}

The exterior of the cells is shown in fig. 3 .

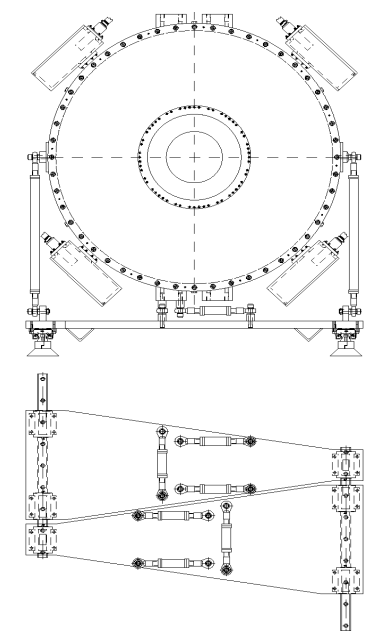

Fig. 3 Cell Exterior and Mounting

Each cell weighs approximately 5 Tonnes and is mounted with a six degree of freedom set of differential screw struts to a base plate. These struts, used at the LBNL Advanced Light Source, allow precision positioning of heavy components. Also shown are the four cans for each cable feed that contain the core compensation circuits. A view of two base plates nested together is also shown with three of the six struts visible. Each cell is individually aligned to the ideal beam line using the struts. Cell to cell and cell to intercell vacuum sealing is done by inflatable bladder units which squeeze face seal O-rings against the cell housing.

\section{ACCELERATOR SYSTEM PERFORMANCE}

The destructive effects of ion production from spilled beam or halo are being minimized by using large beam pipe diameters and possibly scrapers if necessary. Tests on the THOR facility at LANL will be carried out soon to understand the tolerable limits for beam spill on the accelerator cell gaps. Beam tuning will be optimized to stay within those limits. The insulator has been well shielded and conservatively designed to avoid breakdowns.

BBU is being minimized by keeping the pipe size large and using ferrite dampers in the cells to lower the Q's of TM modes. AMOS was used to optimize the cell design for transverse mode impedance and to properly place damping. Mycalex with a dielectric constant of 6.9 makes it more difficult to keep $\mathrm{Z}_{\perp}$ low compared to Rexolite (2.5). Mycalex has been chosen because of its robustness under electrical breakdown both mechanically and in electrical recovery. Tests at LBNL indicated that Rexolite did not recover well from long pulse breakdowns $(\sim 2 \mu \mathrm{s})$. The AMOS modelling indicates a minimum practically achievable $\mathrm{Z}_{\perp}$ of about $350 \Omega \mathrm{m}$ for the standard cells. The injector cells would be lower primarily because of pipe size scaling. Measurements have been carried out on a cavity mock up without Metglas cores and on a full prototype standard cell with cores and oil. The latter used a two wire exciter-loop pickup technique developed by Briggs. ${ }^{(1)}$ The measurements showed a $Z_{\perp}$ at $230 \mathrm{MHz}$ of $350-450 \Omega / \mathrm{m}$ with ferrite damping on the oil side and Q's of 4-5. Measurements using a standard two wire technique ${ }^{(2)}$ will be performed soon to confirm these results.

The total transverse beam motion at the end of the accelerator due to both BBU and corkscrew motion must be less that $10 \%$ of the beam radius. The corkscrew is being minimized by making the accelerating voltage as flat as possible $( \pm 0.5 \%)$ and aligning the solenoids as well as possible using the Stretched Wire Alignment Technique. $^{(3)}$ Accuracies of $\pm 0.1 \mathrm{~mm}$ on solenoid axis location and $\pm 0.3 \mathrm{mrad}$ on tilt should be achievable

A calculation of the beam motion at the end of the machine assuming the configuration discussed above but without intercells has been performed. The calculation assumes a $200 \mathrm{MHz}, 100 \mu$ injector transverse noise seed and a beam-pulse-head-dump which creates a small precursor pulse ahead of the equilibrium pulse. Cell transverse mode impedances of $180 \Omega / \mathrm{m}$ and $340 \Omega / \mathrm{m}$ for the injector and standard cells were used at $200 \mathrm{MHz}$. Q's were 2 and 1.9 respectively. This somewhat pessimistic calculation gave $125 \mu$ of BBU motion superimposed on $350 \mu$ of corkscrew motion. The beam radius was $8 \mathrm{~mm}$ so the transverse motion was well within the $800 \mu$ budget.

\section{REFERENCES}

(1) D. Birx, R. Briggs, L. Reginato, BBU Impedance Measurements on the DARHT-2 Cell, LBNL-42876, February 2, 1999

(2) L.S. Walling, D. E. McMurray, D. V. Neuffer, H. A. Thiessen, Nuc. Inst. Meth., A281, 1989, p.433

(3) L.V. Griffith, F. J. Deadrick, Proc. 1990 Lin. Accel. Conf., Albuquerque, Sept. 1990, p. 423 